\title{
Optimal dynamic production and price for reliability-dependent imperfect production with inventory-level-dependent demand in uncertain environment
}

\author{
Samar Hazari ${ }^{1}$, Kalipada Maity ${ }^{2 *}$, Jayanta Kumar Dey ${ }^{3}$ and Samarjit Kar ${ }^{1}$
}

\footnotetext{
${ }^{*}$ Correspondence:

kalipada_maity@yahoo.co.in

2 Department of Mathematics, Mugberia Gangadhar Mahavidyalaya, Bhupatinagar Purba Medinipur, West Bengal 721425, India

Full list of author information is available at the end of the article
}

\begin{abstract}
An inventory system for reliability-dependent imperfect production is introduced in uncertain environment. The demand rate depends on the stock quantity displayed in the store as well as the sales price. With the goal to realize profit maximization, an optimization problem is addressed to seek for the optimal joint dynamic pricing and production policy which are obtained by solving the optimization problem by Euler-Lagrange equation of optimal control theory. Here, initial selling price, holding cost, and raw material cost are taken as uncertain variables, and using uncertain expectation mathematics, the uncertain variables are converted into crisp value. The numerical results demonstrate the advantages of the joint dynamic one and further show the effects of different system parameters on the optimal dynamic policy and the maximal total profit.
\end{abstract}

Keywords: Dynamic imperfect production; Optimum pricing; Reliability; Euler-Lagrangian equation; Uncertainty theory

\section{Springer}

\section{Introduction}

In classical inventory models, the demand whether deterministic or stochastic was often treated as an exogenous variable, without considering the effect of operating strategy. However, marketing practitioners and researchers have noticed that in many practical cases the demand rate depends on the stock quantity displayed in the store as well as the sales price. Generally, demand rate decreases with sales price yet increases with the stock quantity on display. In recent decades, extensive literature has focused on this phenomenon that demand rate depends on the stock quantity displayed in the store. Levin et al. [1] observed that large piles of consumer goods displayed in a supermarket would lead consumers to buy more. Gupta and Vrat [2] first set up a model to look into this phenomenon where it was assumed that the demand rate was a function of initial stock level. Baker and Urban [3] developed an economic order quantity (EOQ) model with a power-form inventory-level-dependent demand rate, decreasing with the inventory level throughout the sales period. Datta and Pal [4] extended the model developed by Baker and

(c) 2014 Hazari et al.; licensee Springer. This is an Open Access article distributed under the terms of the Creative Commons

Attribution License (http://creativecommons.org/licenses/by/2.0), which permits unrestricted use, distribution, and reproduction in any medium, provided the original work is properly credited. 
Urban [3] on the basis of a hypothesis that the demand rate was dependent on the inventory level until a given level, beyond which it was a constant and the inventory level fell to zero at the end of the order period. Later, Urban [5] modified this model by relaxing the condition of zero-ending inventory. Ray et al. [6] developed an inventory model by assuming that the demand rate was stock dependent and two separate warehouses were used. When the stock level exceeded the capacity [5] gave a comprehensive review of the literature with inventory-level-dependent demand. Recently, Glock et al. [7] have published an optimal ordering policy for stock-dependent demand under progressive payment scheme. Some interesting results about the inventory-level-dependent demand were proposed in [8-15] and so on.

Reliability is closely related with the quality of a product and which is frequently considered a subset of quality. Quality can be defined qualitatively as the amount by which the product satisfies the users' (customers') requirements. Product quality is in part a function of design and conformance to design specifications. On the other hand, reliability is concerned with how long the product continuous to function once it becomes operational. A poor-quality product will likely have poor reliability and a high-quality product will likely have a high reliability. Reliability deals with reducing failures over a time interval and is a measure of the odds for failure-free operation during a given interval, improving reliability occurs at an increase development cost. Mettas [16] developed reliability allocation and optimization for complex systems and later by several researchers such as Panda and Maiti [17], Sarkar [18], and others.

One of the weaknesses of current production-inventory models is the unrealistic assumption that all items produced are of good quality. But production of defective units is a natural phenomenon due to different difficulties in a long-run production process. The production of defective items is increased with time and decreased with reliability parameters. The defective items as a result of imperfect quality production process were initially considered by Porteus [19] and later by several researchers such as Salameh and Jaber [20], Panda et al. [21], Maity et al. [22], Mandal et al. [23], Sana [24], Khan and Jaber [25], Yadav et al. [26], Krishnamoorthi and Panayappan [27], and others.

Uncertainty is common in real-life problems such as randomness, fuzziness, and roughness. Since Liu [28] introduced an uncertainty theory in 2007, it has been well developed and applied in a wide variety of real problems [29]. Recently, Liu [30] proposed an uncertain measure and developed an uncertainty theory which can be used to handle subjective imprecise quantity. Much research work has been done on the development of uncertainty theory and related theoretical work. You [31] proved some convergence theorems of uncertain sequences. Liu [29,32] has defined an uncertainty process and discussed an uncertainty theory. Recently, Jana et al. [33] developed a production-inventory model under permissible delay in payment in uncertain environment. It is often difficult to estimate the initial selling price, holding cost, and raw material cost. Depending upon different aspects, they fluctuate due to uncertainty in judgment, lack of evidence, insufficient information, etc. Sometimes it is not at all possible to get relevant precise data. So, these parameters are assumed to be flexible/imprecise in nature, i.e., uncertain sense and may be represented by uncertain variables.

In this paper, we consider an advertisement policy- and reliability-dependent imperfect production-inventory model in uncertain environment. Using expectation of uncertain number, the uncertain production inventory control problem is converted into equivalent 
crisp production inventory control problem. Then, the problem is solved by the EulerLagrangian equation [34] and GRG technique [35]. The optimum demand, production, and stock levels are determined. The model is illustrated through numerical examples, and results are presented in tabular and graphical form.

\section{Necessary knowledge about uncertain variable}

To better describe the subjective imprecise quantity, Liu [28,29] proposed an uncertain measure and further developed an uncertainty theory which is an axiomatic system of normality, duality, subadditivity, and product measure.

\section{Uncertain measure}

Definition 1. Let us define an uncertain measure $\mathcal{M}$ on the $\sigma$-algebra $\mathcal{L}$. That is, a number $\mathcal{M}\{\Lambda\}$ will be assigned to each event $\{\Lambda\}$ to indicate the belief degree with which we believe $\{\Lambda\}$ will happen. There is no doubt that the assignment is not arbitrary, and the uncertain measure $\mathcal{M}$ must have certain mathematical properties. In order to rationally deal with belief degrees, Liu [28] suggested the following three axioms:

Axiom 1. (Normality axiom) $\mathcal{M}\{\Gamma\}=1$

Axiom 2. (Duality axiom) $\mathcal{M}\{\Lambda\}+\mathcal{M}\left\{\Lambda^{C}\right\}=1$, for any event $\Lambda$

Axiom 3. (Subadditivity axiom) For every countable sequence of events $\Lambda_{1}, \Lambda_{2}, \ldots$, we have

$$
\mathcal{M}\left\{\sum_{i=1}^{\infty} \Lambda_{i}\right\} \leq \sum_{i=1}^{\infty} \mathcal{M}\left\{\Lambda_{i}\right\}
$$

\section{Product uncertain measure}

Product uncertain measure was defined by Liu [29], thus producing the fourth axiom of uncertainty theory. Let $\left(\Gamma_{k}, \mathcal{L}_{k}, \mathcal{M}_{k}\right)$ be uncertainty spaces for $k=1,2, \ldots$ Write $\Gamma=$ $\Gamma_{1} \times \Gamma_{2} \times \ldots$ that is the set of all ordered tuples of the form $\left(\gamma_{1}, \gamma_{2}, \ldots\right)$ where $\gamma_{k} \in \Gamma_{k}$ for $k=1,2, \ldots$. A measurable rectangle in $\Gamma$ is a set $\Lambda=\Lambda_{1} \times \Lambda_{2} \times \ldots$, where $\Lambda_{k} \in \mathcal{L}_{k}$ for $k=1,2, \ldots$. The smallest $\sigma$-algebra containing all measurable rectangles of $\Gamma$ is called the product $\sigma$-algebra, denoted by $\mathcal{L}=\mathcal{L}_{1} \times \mathcal{L}_{2} \times \ldots$ Then, the product uncertain measure $\mathcal{M}$ on the product $\sigma$-algebra $\mathcal{L}$ is defined by the following product axiom [29]:

Axiom 4. (Product axiom) Let $\left(\Gamma_{k}, \mathcal{L}_{k}, \mathcal{M}_{k}\right)$ be uncertainty spaces for $k=1,2, \ldots$. The product uncertain measure $\mathcal{M}$ is an uncertain measure satisfying

$$
\mathcal{M}\left\{\prod_{k=1}^{\infty} \Lambda_{k}\right\} \leq \prod_{k=1}^{\infty} \mathcal{M}\left\{\Lambda_{k}\right\}
$$

where $\Lambda_{k}$ are arbitrarily chosen events from $\mathcal{L}_{k}$ for $k=1,2 \ldots$, respectively.

Definition $2([28])$. The uncertainty distribution $\Phi: R \rightarrow[0,1]$ of an uncertain variable $\widehat{\xi}$ is defined by

$$
\Phi(t)=\mathcal{M}\{\widehat{\xi} \leq t\}
$$


Let $\widehat{\xi} \sim \mathcal{L}(a, b)$ be a linear uncertain variable. This linear uncertain variable is depicted in Figure 1.

Definition 3. Let $\widehat{\xi}$ be an uncertain variable with regular uncertainty distribution $\Phi$. Then, the inverse function $\Phi^{-1}$ is called the inverse uncertainty distribution of $\widehat{\xi}$.

Definition 4 ([28]). Let $\widehat{\xi}$ be an uncertain variable. Then, the expected value of $\widehat{\xi}$ is defined by

$$
E[\widehat{\xi}]=\int_{0}^{\infty} \mathcal{M}\{\widehat{\xi} \geq r\} d r-\int_{-\infty}^{0} \widehat{M}\{\widehat{\xi} \leq r\} d r
$$

provided that at least one of the two integrals is finite.

Theorem 1 ([32]). Let $\widehat{\xi}$ be an uncertain variable with uncertainty distribution $\Phi$. If the expected value exists, then $E[\widehat{\xi}]=\int_{0}^{1} \Phi^{-1}(\alpha) d \alpha$

Theorem 2 ([30]). Let $\xi_{1}, \xi_{2}, \ldots, \xi_{n}$ be independent uncertain variables with uncertainty distributions $\phi_{1}, \phi_{2}, \ldots, \phi_{n}$, respectively. If $f$ is a strictly increasing function, then $\xi=f\left(\xi_{1}, \xi_{2}, \ldots, \xi_{n}\right)$ is an uncertain variable with inverse uncertainty distribution

$$
\Phi^{-1}(\alpha)=f\left(\Phi_{1}^{-1}(\alpha), \Phi_{2}^{-1}(\alpha), \ldots, \Phi_{n}^{-1}(\alpha)\right)
$$

Theorem 3 ([32]). Let $\widehat{\xi}$ and $\widehat{\eta}$ be independent uncertain variables with finite expected values. Then, for any real numbers $a_{1}$ and $a_{2}$, we have

$$
E\left[a_{1} \widehat{\xi}+a_{2} \widehat{\eta}\right]=a_{1} E[\widehat{\xi}]+a_{2} E[\widehat{\eta}]
$$

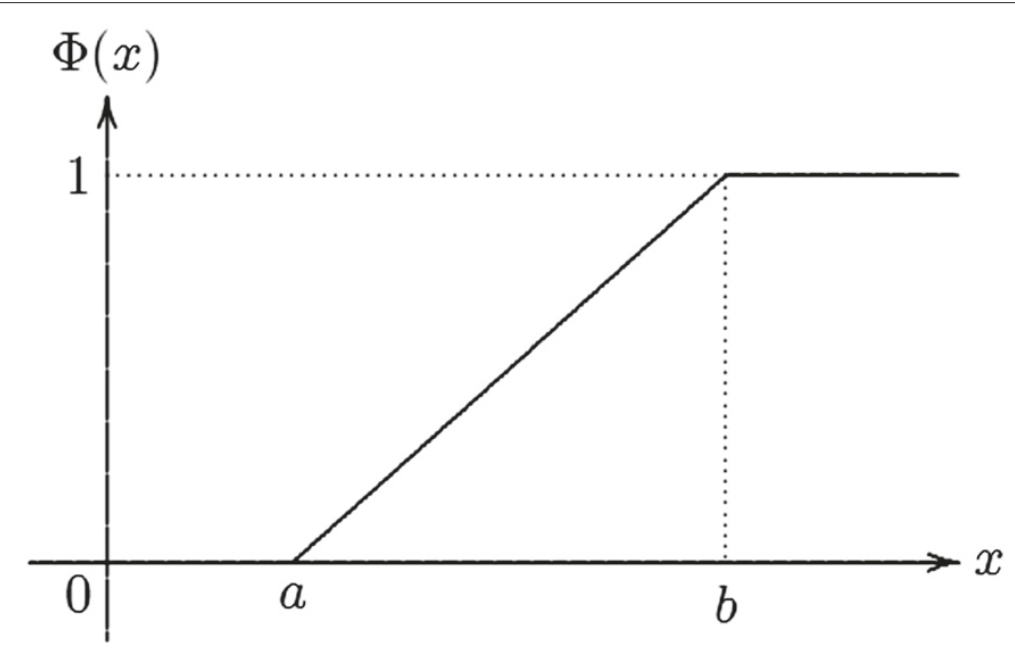

Figure 1 Linear uncertainty variable. 
Lemma 1. Let $\widehat{\xi} \sim \mathcal{L}(a, b)$ be a linear uncertain variable. Then, its inverse uncertainty distribution $\Phi^{-1}(\alpha)=\frac{1}{2}[(1-\alpha) a+b \alpha]$, and it can be expressed as

$$
E[\widehat{\xi}]=\int_{0}^{1} \frac{1}{2}[(1-\alpha) a+b \alpha] d \alpha=\frac{a+b}{2}
$$

\section{Uncertain single-objective programming}

Uncertain programming is a type of mathematical programming involving uncertain variables. Since an uncertain objective function $f(x, \widehat{\xi})$ cannot be directly maximized, we may maximize its expected value. Assume that $x$ is a decision vector, $\widehat{\xi}$ is an uncertain vector, $f$ is an objective function, and $g_{j}$ are constraints functions for $j=1,2, \ldots, p$. Let us examine

$$
\left\{\begin{array}{l}
\max \quad f(x, \widehat{\xi}) \\
\text { subject to }\left\{\begin{array}{l}
g_{j}(x, \widehat{\xi}) \leq 0, j=1,2, \ldots, p \\
x \in X
\end{array}\right.
\end{array}\right.
$$

In order to obtain a decision with maximum expected objective value subject to a set of chance constraints, Liu [28] proposed that the above uncertain programming model (3) is equivalent to the crisp model (4) as follows.

Single-objective programming has been well developed and applied widely. For modelling single-objective decision-making problem with uncertain parameters, Liu [29] presented the following uncertain single-objective programming:

$$
\begin{cases}\max _{x} & (E[f(x, \widehat{\xi}))]) \\ \text { subject to } & \mathcal{M}\left\{g_{j}(x, \widehat{\xi}) \leq 0\right\} \geq \alpha_{j}, j=1,2, \ldots, p\end{cases}
$$

where $f(x, \xi)$ are return functions and $g_{j}(x, \xi)$ are constraint functions for $j=1,2, \ldots, p$.

\section{Optimal control framework}

\section{Assumption and notation}

For an imperfect inventory control model, the following assumptions and notations are used.

\section{Assumptions}

- Selling price and production rates are a function of time which are also taken as control variables.

- Demand rate is dependent linearly on selling price and stock.

- Rate of defectiveness is dependent on reliability.

- This is a single-period inventory model with finite time horizon, $T$.

- Defective units occur only when the item is effectively produced and there is no repair or replacement of defective units over the period [0,T],

- Unit production cost is produced quantity dependent.

- The salvage value price of the finish stock is the same as the selling price.

- The holding cost, raw material cost, and initial selling price are uncertain in nature.

- Shortage is not allowed.

- The inventory level is assumed to be a continuous function of time. 


\section{Notations}

$T=$ time length of the cycle

$U(t)=$ production rate at time $t$ which is a control variable

$s(t)=$ selling price at time $t$ which is a control variable

$\widehat{s_{0}}=\mathcal{L}\left(s_{01}, s_{02}\right)$, linear uncertain selling price at time $t=0$

$X(t)=$ inventory level at time $t$

$D(t)=$ demand rate at time $t$

$C_{u}(R)=M+N e^{k \frac{\left(R-R_{\min }\right)}{\left(R_{\max }-R\right)}}=$ development cost dependent on reliability parameter

$\widehat{C}_{u 0}=\mathcal{L}\left(c_{u 01}, c_{u 02}\right)$, linear uncertain raw material cost

$C_{u 2}=$ wear-tear cost

$C_{p}(R, t)=$ unit production cost which depends on production rate, raw material cost, development cost, and wear-tear cost

$R=$ reliability parameter

$\delta=$ reliability parameter

$\delta e^{(1-R)}=$ reliability-dependent defective rate

$R_{\min }=$ minimum value of the reliability parameter

$R_{\max }=$ maximum value of the reliability parameter

$M=$ the fixed cost like labor and energy costs which is independent of reliability factor $R$ $N=$ the cost of technology, resource, and design complexity for production when $R=$ $R_{\min }$

$\widehat{h}=\mathcal{L}\left(h_{1}, h_{2}\right)$, linear uncertain holding cost per unit item

Proposed optimal dynamic pricing and reliability-dependent imperfect production-inventory model in uncertain environment

In this model, single-item optimal dynamic pricing and reliability-dependent imperfect production-inventory problem is considered. Here, the items are produced at a variable rate $U(t)$ of which $\delta e^{(1-R)}$ (where $\delta e^{(1-R)}<1$ ) is a reliability-dependent defective rate. The reliability $R$ decreases the defective rate and improved the quality of the product. The defective item is treated as disposal part. The demand rate $D(t)$ of customers meet from the inventory. Moreover, $s(t)$ is the selling price of the item

Therefore, the differential equation for stock level $X(t)$ representing the above system during a fixed time horizon, $T$, is

$$
\begin{aligned}
\dot{X}(t) & =\left(1-\delta e^{(1-R)}\right) U(t)-D(t) \\
\text { and } \quad D(t) & =\left\{d_{0}+d_{1} X(t)-d_{2} s(t)\right\}
\end{aligned}
$$

where (.) denotes differentiation.

The unit production cost is considered as a function of produced quantity, raw material cost, wear-tear cost, and development cost. So, the unit production cost is

$$
\widehat{C}_{p}(R, t)=\left(\widehat{C}_{u 0}+\frac{C_{u_{1}}(R)}{U(t)}+C_{u 2} U(t)\right)
$$

Then, the profit function is

$$
\begin{gathered}
\text { Maximize } \widehat{J}=\int_{0}^{T}\left[s(t)\left\{d_{0}+d_{1} x(t)-d_{2} s(t)\right\}-\widehat{h} X(t)\right. \\
\left.-\left(\widehat{C}_{u_{0}} U(t)+C_{u_{1}}(R)+C_{u_{2}} U^{2}(t)\right)\right] d t+s(t) X(T) \\
\text { subject to } X(0)=0 \text { and } X(T)=X_{T}
\end{gathered}
$$


From Equation 5, we get

$$
U(t)=\frac{\dot{X}(t)+d_{0}+d_{1} x(t)-d_{2} s(t)}{\left(1-\delta e^{(1-R)}\right)}
$$

Putting the value of $U(t)$ in (8), we get

$$
\begin{aligned}
\text { Maximize } \widehat{J}= & \int_{0}^{T}\left[s(t)\left\{d_{0}+d_{1} x(t)-d_{2} s(t)\right\}-\widehat{h} X(t)\right. \\
& -\widehat{C}_{u 0}\left\{\frac{\dot{X}(t)+d_{0}+d_{1} x(t)-d_{2} s(t)}{\left(1-\delta e^{(1-R)}\right)}\right\}-C_{u_{1}}(R) \\
& \left.-C_{u_{2}}\left\{\frac{\dot{X}(t)+d_{0}+d_{1} x(t)-d_{2} s(t)}{\left(1-\delta e^{(1-R)}\right)}\right\}^{2}\right] d t+s(t) X(T)
\end{aligned}
$$

subject to $X(0)=0$ and $X(T)=X_{T}$

The above problem is an optimal control problem with control variables $U(t)$ and $s(t)$ in uncertain environment.

\section{The equivalent crisp production control problem}

Using Theorem 3 and Lemma 1, we converted the uncertain production inventory control problem (10) into an equivalent crisp production control problem.

$$
\begin{aligned}
\text { Maximize } E(\widehat{J})= & \int_{0}^{T}\left[s(t) D(t)-E(\widehat{h}) X(t)-\left(E\left(\widehat{c}_{u_{0}}\right) U(t)+C_{u_{1}}(R)+C_{u_{2}} U^{2}(t)\right)\right] d t \\
& +s(T) X(T)
\end{aligned}
$$

subject to $X(0)=0$ and $X(T)=X_{T}$

where $E\left(\widehat{c}_{u 0}\right)=\frac{c_{u 01}+c_{u 02}}{2}, E(\widehat{h})=\frac{h_{1}+h_{2}}{2}$ and $E\left(\widehat{s}_{0}\right)=\frac{s_{01}+s_{02}}{2}$ (using Lemma 1)

\section{Solution method}

The above control problem is solved using Euler-Lagrange equation [34]. Using this theory, we construct the Lagrangian function as

$$
\begin{aligned}
L= & s(t)\left\{d_{0}+d_{1} x(t)-d_{2} s(t)\right\}-E(\widehat{h}) X(t)-E\left(\widehat{C}_{u_{0}}\right)\left\{\frac{\dot{X}(t)+d_{0}+d_{1} x(t)-d_{2} s(t)}{\left(1-\delta e^{(1-R)}\right)}\right\} \\
& -C_{u_{1}}(R)-C_{u_{2}}\left\{\frac{\dot{X}(t)+d_{0}+d_{1} x(t)-d_{2} s(t)}{\left(1-\delta e^{(1-R)}\right)}\right\}^{2}
\end{aligned}
$$

Therefore, our objective is to find out the optimal path of $U(t)$ and $s(t)$ such that $L$ as well as $J$ is maximum.

Lemma 2. The Lagrange function $L$ is maximum in $[0, T]$ for optimum production rate $U(t)=C e^{\frac{d 1}{2 d_{2}} t}-D$

$$
\text { and selling price } s(t)=\left(E\left(\widehat{s}_{0}\right)+\frac{2 d_{2} E(\widehat{h})}{d_{1}}\right) e^{\frac{d 1}{2 d_{2}} t}-\frac{2 d_{2} E(\widehat{h})}{d_{1}}
$$


Proof. For finding the optimal path $U(t)$ and $s(t)$, Euler-Lagrange equation is $U(t)$ and $s(t)$, we get

$$
\begin{aligned}
& \frac{\partial L}{\partial X(t)}-\frac{d}{d t}\left(\frac{\partial L}{\partial \dot{X}(t)}\right)=0 \\
\Rightarrow & d_{1} s(t)-E(\widehat{h})-\frac{d_{1} E\left(\widehat{c}_{u_{0}}\right)}{1-\delta e^{(1-R)}} \\
- & \frac{2 c_{u_{2}} d_{1}}{\left(1-\delta e^{(1-R)}\right)^{2}}\left\{\dot{X}(t)+d_{0}+d_{1} X(t)-d_{2} s(t)\right\} \\
+ & \frac{d}{d t}\left[\frac{E\left(\widehat{c}_{u_{0}}\right)}{1-\delta e^{(1-R)}}\right. \\
+ & \left.\frac{2 c_{u_{2}}}{\left(1-\delta e^{(1-R)}\right)^{2}}\left\{\dot{X}(t)+d_{0}+d_{1} X(t)-d_{2} s(t)\right\}\right]=0 \\
\text { and } & \frac{\partial L}{\partial s(t)}-\frac{d}{d t}\left(\frac{\partial L}{\partial \dot{s}(t)}\right)=0 . \\
\Rightarrow & -2 d_{2} s(t)+\frac{d_{2} E\left(\widehat{c}_{u_{0}}\right)}{1-\delta e^{(1-R)}} \\
+ & \frac{2 c_{u_{2}} d_{2}}{\left(1-\delta e^{(1-R)}\right)^{2}}\left\{\dot{x}(t)+d_{0}+d_{1} x(t)\right\} \\
- & \frac{2 c_{u_{2}} d_{2}^{2}}{\left(1-\delta e^{(1-R)}\right)^{2}} s(t)-\frac{d}{d t}(0)=0 .
\end{aligned}
$$

From Equation 12,

$$
\begin{aligned}
& \dot{X}(t)+d_{0}+d_{1} x(t)-d_{2} s(t)=\frac{\left(1-\delta e^{(1-R)}\right)^{2}}{2 c_{u_{2}} d_{2}}\left[2 d_{2} s(t)\right. \\
& \left.-\frac{E\left(\widehat{c}_{u_{0}}\right) d_{2}}{1-\delta e^{(1-R)}}\right]
\end{aligned}
$$

Using in (13),

$$
\dot{s}(t)-\frac{d_{1}}{2 d_{2}} s(t)=E(\widehat{h})
$$

which is a linear equation whose solution is

$$
s(t)=\left(E\left(\widehat{s}_{0}\right)+\frac{2 d_{2} E(\widehat{h})}{d_{1}}\right) e^{\frac{d 1}{2 d_{2}} t}-\frac{2 d_{2} E(\widehat{h})}{d_{1}}
$$

Solving the above equation, we get the optimal stock level

$$
X(t)=F+G e^{\left(\frac{d_{1}}{2 d_{2}}\right) t}+H e^{-d_{1} t}
$$

Using $X(t)$ in (9), we have

$$
U(t)=C e^{\frac{d 1}{2 d_{2}} t}-D
$$




$$
\text { where } \begin{aligned}
A & =\left\{d_{2}+\frac{\left(1-\delta e^{(1-R)}\right)^{2}}{c_{u_{2}}}\right\}\left(E\left(\widehat{s}_{0}\right)+\frac{2 d_{2} E(\widehat{h})}{d_{1}}\right) \\
B & =\frac{2 d_{2} E(\widehat{h})}{d_{1}}\left\{d_{2}+\frac{\left(1-\delta e^{(1-R)}\right)^{2}}{c_{u_{2}}}\right\}+d_{0}+\frac{E\left(\widehat{c}_{u_{0}}\right)\left(1-\delta e^{(1-R)}\right)}{2 c_{u_{2}}} \\
C & =\left(E\left(\widehat{s}_{0}\right)+\frac{2 d_{2} E(\widehat{h})}{d_{1}}\right) \frac{\left(1-\delta e^{(1-R)}\right)}{c_{u_{2}}} \\
D & =\frac{2 d_{2} E(\widehat{h})}{d_{1}} \frac{\left(1-\delta e^{(1-R)}\right)}{c_{u_{2}}}+\frac{E\left(\widehat{c}_{u_{0}}\right)}{2 c_{u_{2}}} \\
F & =\frac{B}{d_{1}} \\
G & =\frac{2 A d_{2}}{d_{1}\left(1+2 d_{2}\right)} \\
\text { and } H & =X_{0}-\frac{2 A d_{2}}{d_{1}\left(1+2 d_{2}\right)}-\frac{B}{d_{1}}
\end{aligned}
$$

The maximum value of $J$ is given by

$$
\begin{aligned}
J= & \int_{0}^{T}\left[s^{*}(t) D(t)-E(\widehat{h}) X^{*}(t)-\left(E\left(\widehat{c}_{u_{0}}\right) U^{*}(t)+C_{u_{1}}(R)+C_{u_{2}}\left(U^{*}(t)\right)^{2}\right] d t+s(t) X^{*}(T)\right. \\
= & d_{0}\left[\left(E\left(\widehat{s}_{0}\right)+\frac{2 d_{2} E(\widehat{h})}{d_{1}}\right) \frac{d 1}{2 d_{2}}\left(e^{\frac{d 1}{2 d_{2}} T}-1\right)-\frac{2 d_{2} E(\widehat{h})}{d_{1}} T\right] \\
& +d_{1}\left[( E ( \widehat { s _ { 0 } } ) + \frac { 2 d _ { 2 } E ( \widehat { h } ) } { d _ { 1 } } ) \left\{F \frac{2 d_{2}}{d_{1}}\left(e^{\frac{d 1}{2 d_{2}} T}-1\right)\right.\right. \\
& \left.+G \frac{d_{2}}{d_{1}}\left(e^{\frac{d 1}{d_{2}} T}-1\right)+\frac{2 H d_{2}}{d_{1}\left(1-2 d_{2}\right)}\left(e^{\left(\frac{d 1}{d_{2}}-d_{1}\right) T}-1\right)\right\} \\
& \left.-\frac{2 d_{2} E(\widehat{h})}{d_{1}}\left\{F T+G \frac{2 d_{2}}{d_{1}}\left(e^{\frac{d 1}{2 d_{2}} T}-1\right)+\frac{H}{d_{1}}\left(1-e^{d_{1} T}\right)\right\}\right] \\
& -d_{2}\left[\left(E\left(\widehat{s}_{0}\right)+\frac{2 d_{2} E(\widehat{h})}{d_{1}}\right)^{2} \frac{d_{2}}{d_{1}}\left(e^{\frac{d 1}{d_{2}} T}-1\right)-\frac{8 d_{2}^{2} E(\widehat{h})}{d_{1}^{2}}\left(E\left(\widehat{s}_{0}\right)+\frac{2 d_{2} E(\widehat{h})}{d_{1}}\right)\left(e^{\frac{d 1}{2 d_{2}} T}-1\right)\right. \\
& +\frac{4 d_{2}^{2} E(\widehat{h})^{2}}{d_{1}^{2}} T-E(\widehat{h})\left[F T+G \frac{2 d_{2}}{d_{1}}\left(e^{\frac{d 1}{2 d_{2}} T}-1\right)+\frac{H}{d_{1}}\left(1-e^{d_{1} T}\right)\right] \\
& -E\left(\widehat{c}_{u_{0}}\right)\left[\frac{2 C d_{2}}{d_{1}}\left(e^{\frac{d 1}{2 d_{2}} T}-1\right)-D T\right]-\left\{M+N e^{k \frac{\left(R-R_{\min }\right)}{\left(R_{\max }-R\right)}}\right\} T-c_{u_{2}}\left[C^{2} \frac{d_{2}}{d_{1}}\left(e^{\frac{d 1}{d_{2}} T}-1\right)\right. \\
& \left.-\frac{4 C D d_{2}}{d_{1}}\left(e^{\frac{d 1}{2 d_{2}} T}-1\right)+D^{2} T\right]+s(t) X(T)
\end{aligned}
$$

\section{Particular case when demand depends only on selling price in uncertain environment}

In this case, the stock depends only on the selling price. The demand rate $D(t)$ of customers meets from the inventory.

Therefore, the differential equation for stock level $X(t)$ representing the above system during a fixed time horizon, $T$, is

$$
\begin{aligned}
\dot{X}(t) & =\left(1-\delta e^{(1-R)}\right) U(t)-D(t) \\
\text { and } \quad D(t) & =\left\{d_{0}-d_{2} s(t)\right\}
\end{aligned}
$$


where (.) denotes differentiation.

The unit production cost is considered as a function of produced quantity, raw material cost, wear-tear cost, and development cost. So, the unit production cost is

$$
\widehat{C}_{p}(R, t)=\left(\widehat{C}_{u 0}+\frac{C_{u_{1}}(R)}{U(t)}+C_{u 2} U(t)\right)
$$

Then, the profit function is

$$
\begin{aligned}
\text { Maximize } \widehat{J}= & \int_{0}^{T}\left[s(t)\left\{d_{0}-d_{2} s(t)\right\}-\widehat{h} X(t)\right. \\
& \left.-\left(\widehat{C}_{u_{0}} U(t)+C_{u_{1}}(R)+C_{u_{2}} U^{2}(t)\right)\right] d t
\end{aligned}
$$

subject to $X(0)=0$ and $X(T)=X_{T}$

From Equation 15, we get

$$
U(t)=\frac{\dot{X}(t)+d_{0}-d_{2} s(t)}{\left(1-\delta e^{(1-R)}\right)}
$$

Putting the value of $U(t)$ in (18), we get

$$
\begin{aligned}
\text { Maximize } \widehat{J}= & \int_{0}^{T}\left[s(t)\left\{d_{0}-d_{2} s(t)\right\}-\widehat{h} X(t)\right. \\
& -\widehat{C}_{u 0}\left\{\frac{\dot{X}(t)+d_{0}-d_{2} s(t)}{\left(1-\delta e^{(1-R)}\right)}\right\}-C_{u_{1}}(R) \\
& \left.-C_{u_{2}}\left\{\frac{\dot{X}(t)+d_{0}-d_{2} s(t)}{\left(1-\delta e^{(1-R)}\right)}\right\}^{2}\right] d t+s(t) X(T)
\end{aligned}
$$

subject to $X(0)=0$ and $X(T)=X_{T}$

The above problem is an optimal control problem with uncertain control variables $U(t)$, uncertain holding cost $h$, and uncertain initial selling price, i.e., $s_{0}=s(0)$.

\section{The equivalent crisp production control problem}

Using Theorem 3 and Lemma 1, we converted the uncertain production inventory control problem (20) into an equivalent crisp production control problem.

$$
\begin{aligned}
\text { Maximize } E \widehat{J})= & \int_{0}^{T}\left[s(t) D(t)-E(\widehat{h}) X(t)-\left(E\left(\widehat{c}_{u_{0}}\right) U(t)+C_{u_{1}}(R)+C_{u_{2}} U^{2}(t)\right)\right] d t \\
& +s(T) X(T)
\end{aligned}
$$

subject to $X(0)=0$ and $X(T)=X_{T}$

where $E\left(\widehat{c}_{u 0}\right)=\frac{c_{u 01}+c_{u 02}}{2}, E(\widehat{h})=\frac{h_{1}+h_{2}}{2}$, and $E\left(\widehat{s}_{0}\right)=\frac{s_{01}+s_{02}}{2}$ (using Lemma 1$)$.

\section{Solution method}

The above control problem is solved using Euler-Lagrange equation [34]. Using this theory, we construct the Lagrangian function as

$$
\begin{aligned}
L= & s(t)\left\{d_{0}-d_{2} s(t)\right\}-E(\widehat{h}) X(t)-E\left(\widehat{C}_{u_{0}}\right)\left\{\frac{\dot{X}(t)+d_{0}-d_{2} s(t)}{\left(1-\delta e^{(1-R)}\right)}\right\} \\
& -C_{u_{1}}(R)-C_{u_{2}}\left\{\frac{\dot{X}(t)+d_{0}-d_{2} s(t)}{\left(1-\delta e^{(1-R)}\right)}\right\}^{2}
\end{aligned}
$$


Therefore, our objective is to find out the optimal path of $U(t)$ and $s(t)$ such that $L$ as well as $J$ is maximum.

Lemma 3. The Lagrangian function $L$ is maximum in $[0, T]$ for optimum production rate $U(t)=\frac{R_{1} t+S}{1-\delta}$ and selling price $s(t)=\frac{E(\widehat{h}) d_{2} t+Q}{P}$

Proof. For finding the optimal path $U(t)$ and $s(t)$ Euler-Lagrange equation of $U(t)$ and $s(t)$, we get

$$
\begin{array}{cl} 
& \frac{\partial L}{\partial X(t)}-\frac{d}{d t}\left(\frac{\partial L}{\partial \dot{X}(t)}\right)=0 \\
\Rightarrow & -E(\widehat{h})-\frac{2 c_{u_{2}}}{(1-\delta)^{2}}\left\{\dot{X}(t)+d_{0}-d_{2} s(t)\right\}=0 \\
\text { and } \quad & \frac{\partial L}{\partial s(t)}-\frac{d}{d t}\left(\frac{\partial L}{\partial \dot{s}(t)}\right)=0 \\
\Rightarrow & d_{0}-d_{2} s(t)+\frac{d_{2} E\left(\widehat{c}_{u_{0}}\right)}{1-\delta} \\
& +\frac{2 d_{2} c_{u_{2}}}{(1-\delta)^{2}}\left\{\dot{X}(t)+d_{0}-d_{2} s(t)\right\}=0
\end{array}
$$

Solving Equations 22 and 23, we get

$$
\begin{aligned}
& s(t)=\frac{E(\widehat{h}) d_{2} t+Q}{P}, \\
& U(t)=\frac{R_{1} t+S}{1-\delta}, \\
& \text { and } \quad x(t)=Y t^{2}+Z t \text {, } \\
& \text { where } P=2 d_{2}+\frac{2 c_{u_{2}}^{2} d_{2}^{2}}{(1-\delta)^{2}} \text {, } \\
& Q=\frac{2 c_{u_{2}}^{2} d_{2}^{2}}{T(1-\delta)^{2}}\left\{X_{T}-\frac{E(\widehat{h})(1-\delta)^{2} T^{2}}{4 c_{u_{2}}}\right\} \\
& +d_{0}+\frac{d_{2} E\left(\widehat{c}_{u_{0}}\right)}{1-\delta} \\
& +\frac{2 c_{u_{2}}^{2} d_{2}^{2}}{(1-\delta)^{2}} \\
& R_{1}=\frac{E(\widehat{h})(1-\delta)^{2}}{2 c_{u_{2}}}-\frac{d_{2}^{2} E(\widehat{h})}{P}, \\
& S=\frac{1}{T}\left\{X_{T}-\frac{E(\widehat{h})(1-\delta)^{2} T^{2}}{4 c_{u_{2}}}\right\}-d_{0}-\frac{d_{2} Q}{P(1-\delta)}, \\
& Y=\frac{E(\widehat{h})(1-\delta)^{2}}{4 c_{u_{2}}}, \\
& \text { and } Z=\frac{1}{T}\left\{X_{T}-\frac{E(\widehat{h})(1-\delta)^{2} T^{2}}{4 c_{u_{2}}}\right\}
\end{aligned}
$$

\section{Table 1 The uncertain input data}

\begin{tabular}{lcc}
\hline Uncertain parameters & $\begin{array}{c}\text { Linear uncertain values } \\
(\mathbf{U S} \mathbf{\$})\end{array}$ & $\begin{array}{c}\text { Expectation of uncertain parameters } \\
(\text { US } \mathbf{)})\end{array}$ \\
\hline Initial selling price $\left(\widehat{S_{0}}\right)$ & $(8,12)$ & 10 \\
Holding cost $(\widehat{h})$ & $(0.4,0.8)$ & 0.6 \\
Raw material cost $\left(\widehat{C}_{u 0}\right)$ & $(1,3)$ & 2 \\
\hline
\end{tabular}


Table 2 The crisp input data

\begin{tabular}{cccccccccccc}
\hline $\boldsymbol{M}$ & $\begin{array}{c}\boldsymbol{N} \\
\text { (US\$) }\end{array}$ & $\begin{array}{c}\boldsymbol{c}_{\boldsymbol{u} \mathbf{2}} \\
(\mathbf{U S} \mathbf{)})\end{array}$ & $\begin{array}{c}\boldsymbol{k} \\
(\mathbf{U S} \mathbf{\text { ) }})\end{array}$ & $\boldsymbol{R}_{\min }$ & $\boldsymbol{R}_{\max }$ & $\boldsymbol{\delta}$ & $\boldsymbol{d}_{\mathbf{0}}$ & $\boldsymbol{d}_{\mathbf{1}}$ & $\boldsymbol{d}_{\mathbf{2}}$ & $\boldsymbol{X}_{\mathbf{0}}$ & $\boldsymbol{T}$ \\
\hline 20 & 5 & 0.03 & 0.5 & 0.5 & 0.95 & 0.02 & 20 & 0.03 & 0.3 & 0 & 8
\end{tabular}

The maximum value of $J$ is given by

$$
\begin{aligned}
J= & \int_{0}^{T}\left[s^{*}(t) D(t)-E(\widehat{h}) X^{*}(t)-\left(E\left(\widehat{c}_{u_{0}}\right) U^{*}(t)+C_{u_{1}}(R)+C_{u_{2}}\left(U^{*}(t)\right)^{2}\right] d t+s^{*}(t) X^{*}(T)\right. \\
= & \frac{d_{0}}{P}\left[\frac{E(\widehat{h}) d_{2} T^{2}}{2}+Q T\right]+\frac{d_{2}}{P^{2}}\left[\frac{E(\widehat{h})^{2} d_{2}^{2} T^{3}}{3}+\frac{2 Q E(\widehat{h}) d_{2} T^{2}}{2}+Q^{2} T\right]-E(\widehat{h})\left[\frac{Y T^{3}}{3}+\frac{Z T^{2}}{2}\right] \\
& -\frac{E\left(\widehat{c}_{u_{0}}\right)}{1-\delta}\left[\frac{R T^{2}}{2}+S T\right]-c_{u_{1}}(R)-\frac{c_{u_{2}}}{(1-\delta)^{2}}\left[\frac{R^{2} T^{3}}{3}+R S T^{2}+S^{2} T\right]+s(t) X(T)
\end{aligned}
$$

\section{Numerical illustration}

To illustrate the above reliability-dependent uncertain production inventory model numerically, we consider uncertain and crisp input data given in Tables 1 and 2, respectively. For these uncertain and crisp input data, the optimum demand rate $D^{*}(t)$, production rate $u^{*}(t)$, and stock level $X^{*}(t)$ are given in Table 3 and shown in Figures 2,3,4, respectively.

\section{Uncertain input data}

The uncertain input data for advertisement cost, holding cost, and selling price and their expectation values by using Lemma 3 are given in Table 1.

\section{Crisp input data}

The other crisp inventory data are given in Table 2 .

Optimum result

For the above uncertain and crisp input data, the optimum demand rate $D^{*}(t)$, production rate $u^{*}(t)$, and stock level $X^{*}(t)$ are given in Table 3 and shown in Figures 2,3,4, respectively. Also, the optimum results are $R^{*}=0.7521, J^{*}=U S \$ 5,540.72, X^{*}(t)=3,095.54$

Table 3 Optimal values of demand, production, and stock level with relation to time

\begin{tabular}{cccccc}
\hline $\boldsymbol{t}$ & $\boldsymbol{J}^{*}(\boldsymbol{t})$ & $\boldsymbol{X}^{*}(\boldsymbol{t})$ & $\boldsymbol{U}^{*}(\boldsymbol{t})$ & $\boldsymbol{D}^{*}(\boldsymbol{t})$ & $\boldsymbol{s}^{*}(\boldsymbol{t})$ \\
\hline 0 & 0 & 0 & 291.46 & 17 & 10 \\
1 & -264.90 & 280.11 & 328.09 & 25.08 & 11.13 \\
2 & -386.49 & 589.54 & 366.61 & 34.00 & 12.31 \\
3 & -312.01 & 927.50 & 407.09 & 43.76 & 13.56 \\
4 & 20 & $1,295.73$ & 449.66 & 54.41 & 14.87 \\
5 & 682.33 & $1,695.36$ & 494.41 & 65.91 & 16.25 \\
6 & $1,757.00$ & $2,127.56$ & 541.45 & 78.52 & 17.69 \\
7 & $3,339.92$ & $2,593.92$ & 590.90 & 92.05 & 19.22 \\
8 & $5,540.72$ & $3,095.54$ & 642.88 & 106.62 & 20.82 \\
\hline
\end{tabular}




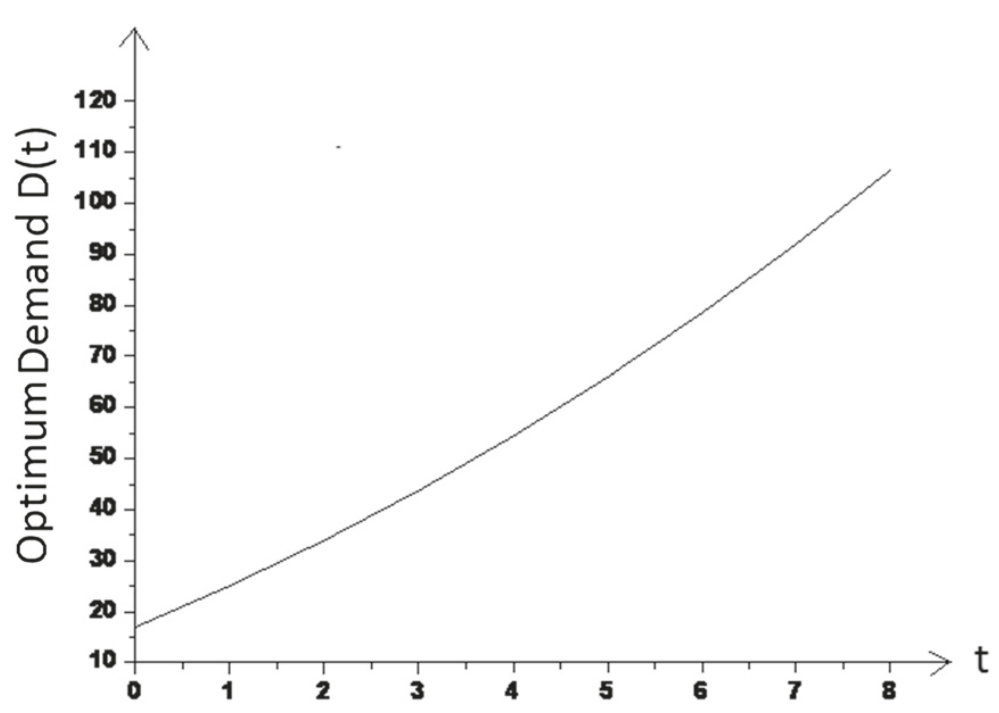

Figure 2 Optimum demand versus time.

units, $s^{*}(t)=20.82$ units, $D^{*}(t)=106.62$ units, and $U^{*}(t)=642.88$ units. The optimum profit versus time are also shown in Figure 5 . The optimum profit versus reliability are given in Figure 6. The optimum selling price versus time are given in Figure 7.

\section{Numerical illustration for particular cases}

To illustrate the above reliability-dependent production inventory model numerically, we consider the previous uncertain and crisp input data which are already given in Tables 1 and 2 , respectively.

\section{Optimum result}

For the previous uncertain and crisp input data and using Lemma 3, the optimum result is obtained as $R^{*}=0.5, J^{*}=\mathrm{US} \$ 108,296.10, X^{*}(t)=3,095.54$ units, $s^{*}(t)=48.16$ units, $D^{*}(t)=5.55$ units, and $U^{*}(t)=402.71$ units.

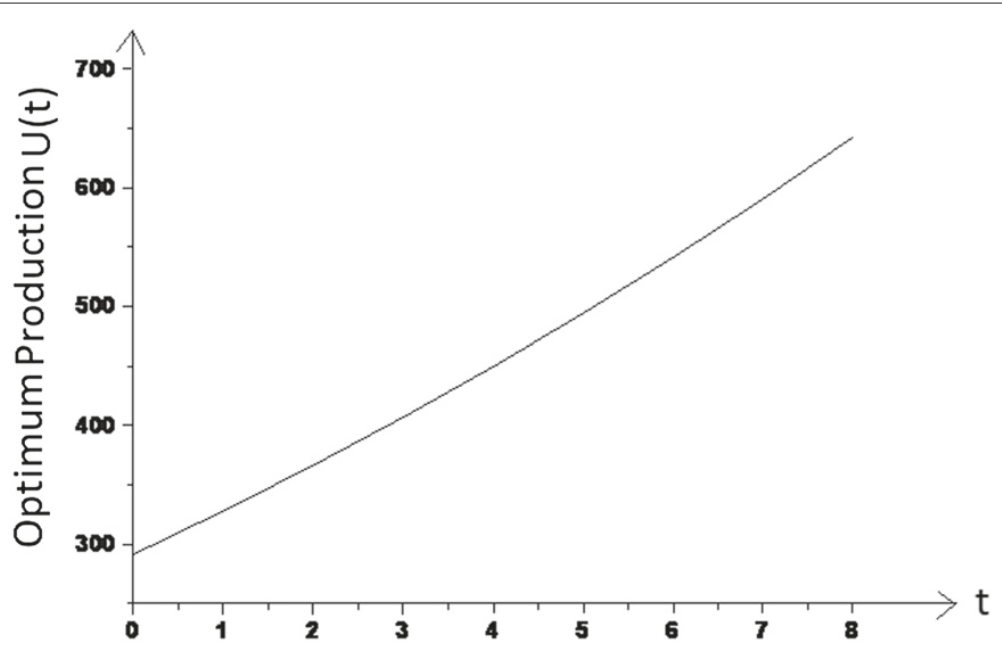

Figure 3 Optimum production rate versus time. 


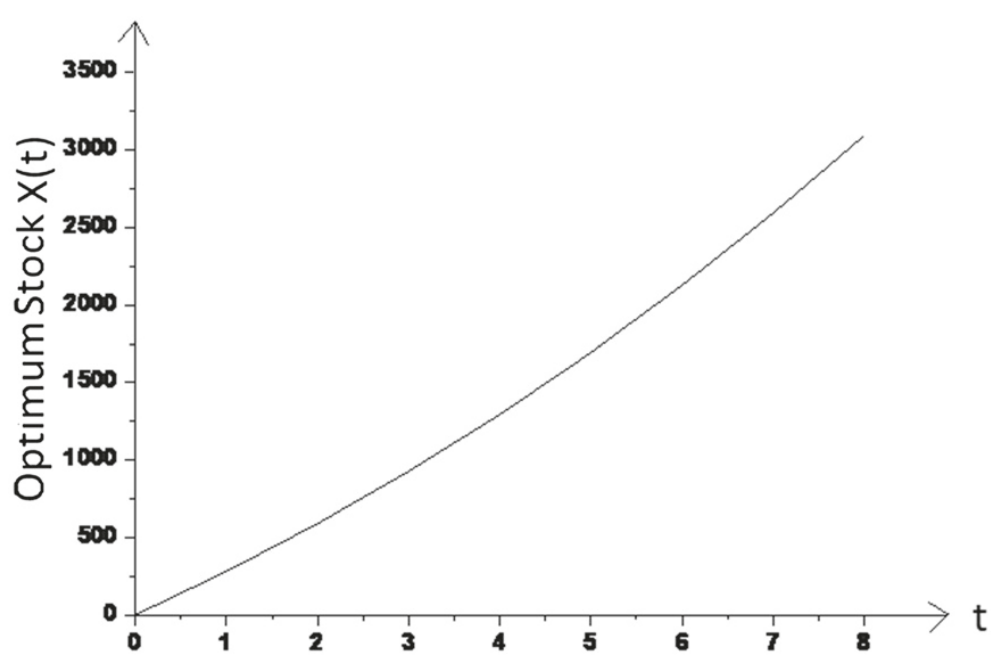

Figure 4 Optimum stock versus time.

\section{Practical implications}

A washing machine fails, a car battery goes dead, a toaster oven electrical plug burns, a water heater leaks, a floppy disk drive goes bad, a TV remote control quits functioning, a stergo amplifier quits, an automobile engine starter fails, and a house roof leaks are commonly experienced by the customers. These failures, however, are much more significant in both their economical and safety effects.

From the above examples, one can conclude that the impact of product and system failures varies from minor inconvenience and costs to personal injury, significant economical loss, and death. Causes of these failures include bad engineering design, faculty construction, human error, improper use, and lack of protection against excessive environmental stress. Under current laws and recent court decisions, the manufacturing can be held liable for failure to account properly for product safety and reliability. Moreover,

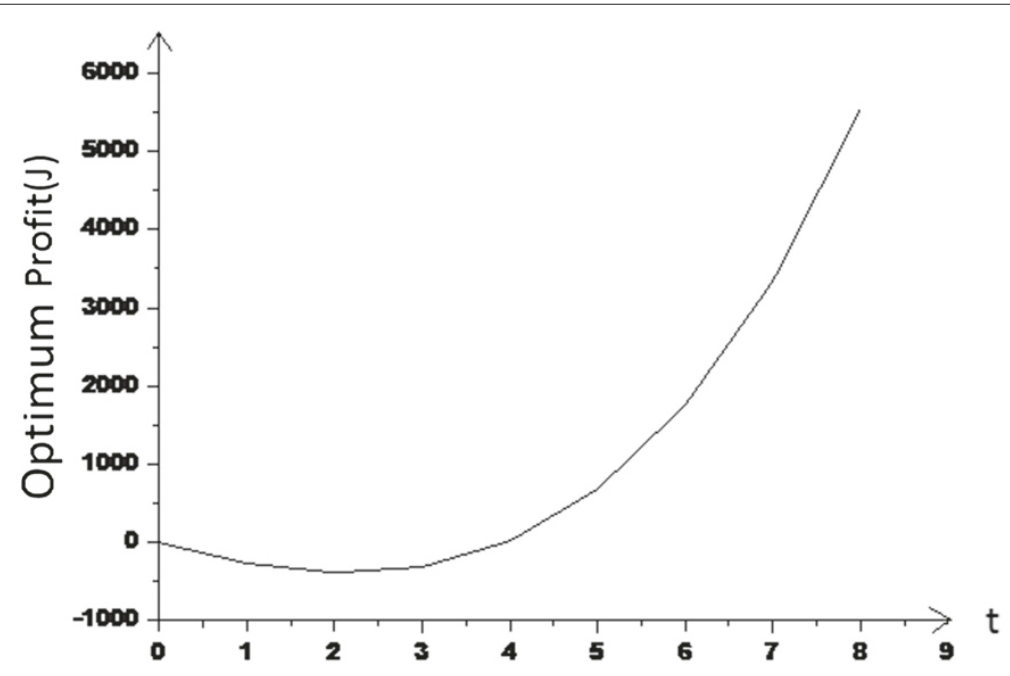

Figure 5 Optimum profit versus time. 


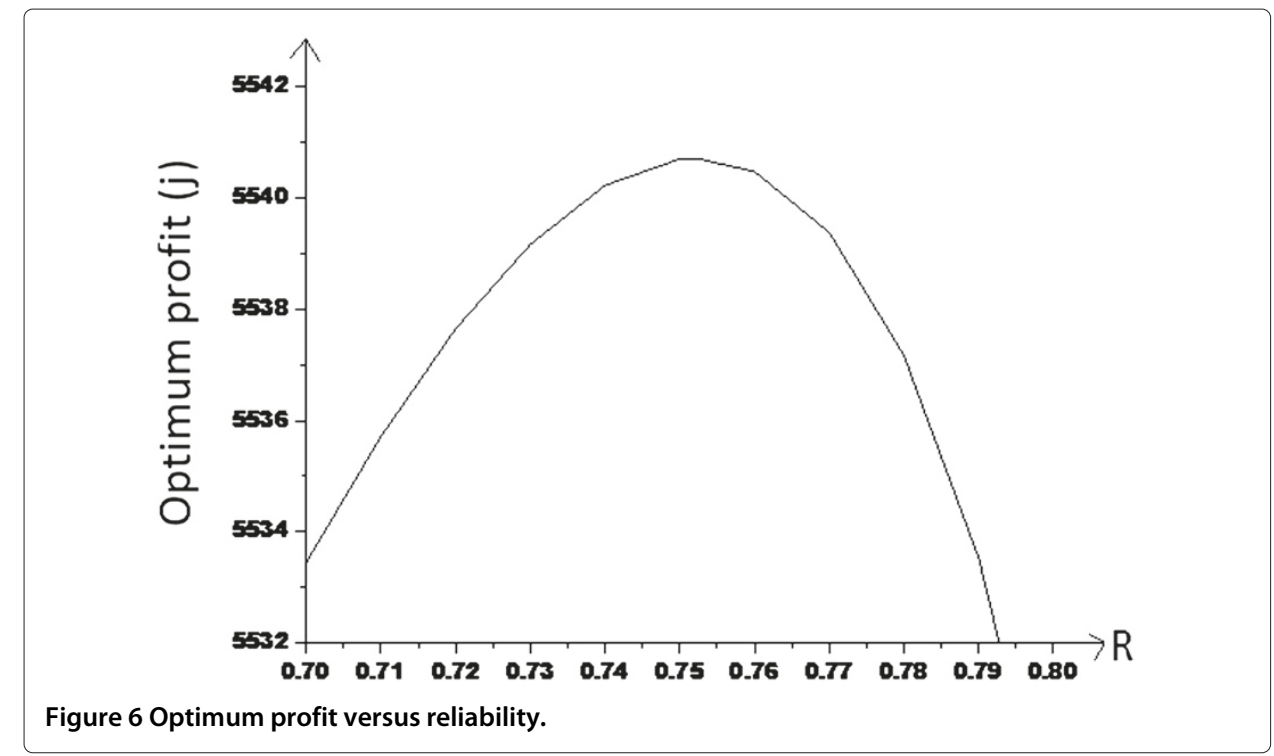

the demand of these product are advertisement dependent. Also, the selling price fluctuated day by day, so it is taken as uncertain in nature. So, this model is practically applicable for such type of imperfect production inventory problems.

\section{Conclusion}

The present paper first time deals with the optimum production and advertising policy for a single-item production inventory system with reliability-dependent defective rate, reliability- and production rate-dependent unit production cost, depreciation rate of sales, marginal selling price of finish stock, and dynamic demand under uncertain environment. Also, some ideas such as (i) optimal control production problem for defective multi-items, (ii) advertisement-dependent demand, (iii) dynamic production function,

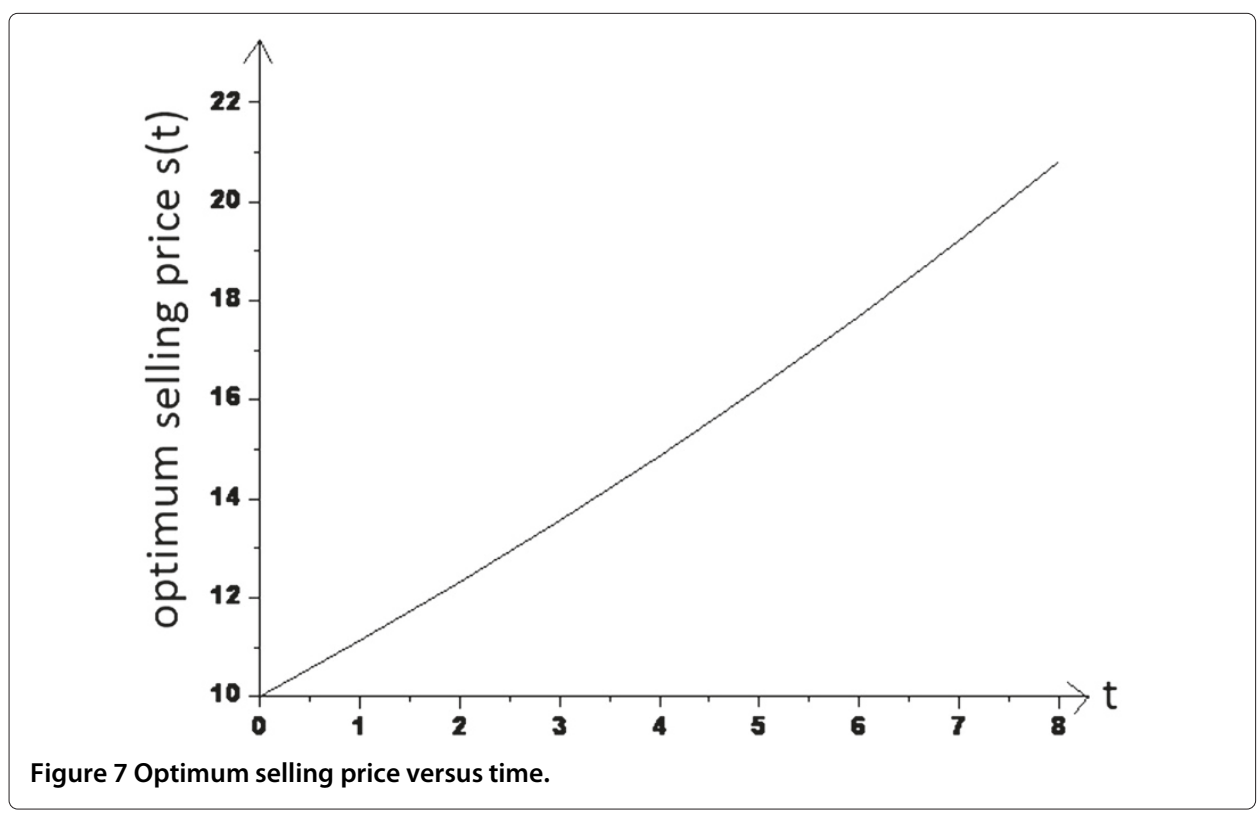


and (iv) production quantity-dependent unit cost. In the solution approach, the new ideas are reliability and uncertain expectation. In this connection, the theories 1,2 , and 3 and Lemma 1 for uncertain variable are established and used in optimal control problem. The formulation and analysis presented here can be extended to other production-inventory problems with different types of demand, advertisement, deterioration, defective, price discount, etc.

\section{Acknowledgements}

Dr. Jayanta Kumar Dey thanks the Minor Research Project (PSW-138/09-10, Government of India) for the financial support to do this research work.

\section{Author details}

${ }^{1}$ Department of Mathematics, National Institute of Technology, Durgapur, West Bengal 713209, India. ${ }^{2}$ Department of Mathematics, Mugberia Gangadhar Mahavidyalaya, Bhupatinagar Purba Medinipur, West Bengal 721425, India.

${ }^{3}$ Department of Mathematics, Mahisadal Raj College, Purba-Medinipur, West Bengal 721628, India.

Received: 16 November 2013 Accepted: 28 March 2014

Published: 24 April 2014

\section{References}

1. Levin, RT, McLaughlin, CP, Lamone, RP, Kottas, JF: Production operations management: contemporary policy for managing operating systems. McGraw-Hill, New York (1972)

2. Gupta, R, Vrat, P: Inventory model for stock-dependent consumption rate. Opsearch. 23, 19-24 (1986)

3. Baker, RC, Urban, TL: A deterministic inventory system with an inventory-level-dependent demand rate. J. Oper. Res. Soc. 39, 823-831 (1988)

4. Datta, TK, Pal, AK: A note on an inventory model with inventory-level-dependent demand rate. J. Oper. Res. Soc. 41, 971-975 (1990)

5. Urban, TL: Inventory models with inventory-level-dependent demand: a comprehensive review and unifying theory. Eur. J. Oper. Res. 162, 792-804 (2005)

6. Ray, J, Goswami, A, Chaudhuri, KS: On an inventory model with two levels of storage and stock-dependent demand rate. Int. J. Syst. Sci. 29, 249-254 (1998)

7. Glock, CH, Ries, JM, Schwindl, K: A note on optimal ordering policy for stock-dependent demand under progressive payment scheme. Eur J. Oper. Res. 232, 423-426 (2014)

8. Zhou, YW, Min, J, Goyal, SK: Supply-chain coordination under an inventory-level-dependent demand rate. Int. J. Prod. Econ. 113, 518-527 (2008)

9. Sajadieh, MS, Thorstenson, A, Jokar, MA: An integrated vendor-buyer model with stock-dependent demand. Transportation Res. Part E: Logistics Transportation Rev. 46, 963-974 (2010)

10. Hsieh, TP, Dye, CY, Ouyang, LY: Optimal lot size for an item with partial backlogging rate when demand is stimulated by inventory above a certain stock level. Math. Comput. Model. 51, 13-32 (2010)

11. Dey, JK, Mondal, SK, Maiti, M: Two storage inventory problem with dynamic demand and interval valued lead-time over finite time horizon under inflation and time-value of money. 185, 170-194 (2008)

12. Pando, V, Garcűşa-Laguna, J, San-Josqe, LA: Optimal policy for profit maximising in an EOQ model under non-linear holding cost and stock-dependent demand rate. Int. J. Syst. Sci. 43, 2160-2171 (2012)

13. Kim, T, Glock, CH: A multi-stage joint economic lot size model with lead time penalty costs. Comput. Ind. Eng. $\mathbf{6 6}$ 133-146 (2013)

14. Jana, DK, Maity, K, Das, B, Roy, TK: A fuzzy simulation via contractive mapping genetic algorithm approach to an imprecise production inventory model under volume flexibility. J. Simul. 7, 90-100 (2013)

15. Maity, K: A supply-chain production inventory model with warehouse facilities under fuzzy environment. In: Kahraman, C, Oztaysi, B (eds.) Supply Chain Management Under Fuzziness, pp. 517-551. Springer, Heidelberg (2014)

16. Mettas, A: Reliability allocation and optimization for complex system, reliability and maintainability symposium. Relia Soft Corporation, Los Angeles (2000)

17. Panda, D, Maiti, M: Multi-item inventory models with price dependent demand under flexibility and reliability consideration and imprecise space constraint: a geometric programming approach. Math. Comput. Model. 49 1733-1749 (2009)

18. Sarkar, B: An inventory model with reliability in an imperfect production process. Appl. Math. Comput. 218 4881-4891 (2012)

19. Porteus, EL: Optimal lot sizing, process quality improvement and setup cost reduction. Oper. Res. 34, 137-144 (1986)

20. Salameh, MK, Jaber, MY: Economic production quantity model for items with imperfect quality. Int. J. Prod. Econ. 64, 59-64 (2000)

21. Panda, D, Kar, S, Maity, K, Maity, M: A single period inventory model with imperfect production and stochastic demand under chance and imprecise constraints. Eur. J. Oper. Res. 188, 121-139 (2008)

22. Maity, AK, Maity, K, Maiti, M: Optimal remanufacturing control policy with defective items. International J. Oper. Res. 6, 500-518 (2009)

23. Mandal, S, Maity, K, Mondal, S, Maiti, M: Optimal production inventory policy for defective items with fuzzy time period. Appl. Math. Model. 34, 810-822 (2010)

24. Sana, SS: A production-inventory model of imperfect quality products in a three-layer supply chain. Decis. Support Syst. 50, 539-547 (2011) 
25. Khan, M, Jaber, MY: Optimal inventory cycle in a two-stage supply chain incorporating imperfect items from suppliers. Int. J. Oper. Res. 10, 442-457 (2011)

26. Yadav, D, Singh, SR, Kumari, R: Three-stage supply chain coordination under fuzzy random demand and production rate with imperfect production process. Int. J. Oper. Res. 16, 421-447 (2013)

27. Krishnamoorthi, C, Panayappan, S: An EPQ model for an imperfect production system with rework and shortages. Int. J. Oper. Res. 17, 104-124 (2013)

28. Liu, B: Uncertainty Theory. 2nd edn. Springer-Verlag, Berlin (2007)

29. Liu, B: Some research problems in uncertainty theory. J. Uncertain Syst. 3, 3-10 (2009)

30. Liu, B: Uncertainty Theory: a Branch of Mathematics for Modeling Human Uncertainty. Springer, Berlin (2010)

31. You, C: Some convergence theorems of uncertain sequences. Math. Comput. Model. 49, 482-487 (2009)

32. Liu, B: Fuzzy process, hybrid process and uncertain process. J. Uncertain Syst. 2, 3-16 (2008)

33. Jana, DK, Maity, K, Roy, TK, J. Uncertainty Anal. Appl: A three-layer supply chain integrated production-inventory model under permissible delay in payments in uncertain environments. 1, 1-17 (2013)

34. Macki, J: Strauss, A: Introduction to Optimal Control. Springer, Berlin (1982)

35. Gabriel, GA, Ragsdell, KM: The generalized reduced gradient method. AMSE J. Eng. Ind. 99, 384-400 (1977)

\section{doi:10.1186/2195-5468-2-9}

Cite this article as: Hazari et al:: Optimal dynamic production and price for reliability-dependent imperfect production with inventory-level-dependent demand in uncertain environment. Journal of Uncertainty Analysis and Applications 2014 2:9.

\section{Submit your manuscript to a SpringerOpen ${ }^{\circ}$ journal and benefit from:}

- Convenient online submission

- Rigorous peer review

- Immediate publication on acceptance

Open access: articles freely available online

- High visibility within the field

- Retaining the copyright to your article

Submit your next manuscript at $\boldsymbol{\wedge}$ springeropen.com 